\title{
Effects of ingesting Dyma-Burn Xtreme, a thermogenic dietary supplement on metabolic rate and subjective measures of mood state
}

\author{
Stacie Urbina ${ }^{1}$, Craig Jones ${ }^{1}$, Sara Hayward ${ }^{1}$, Cliffa Foster ${ }^{1}$, Shawn Wells ${ }^{2}$, Rob Wildman², Bill Campbell ${ }^{3}$, \\ Lem Taylor ${ }^{1}$, Colin Wilborn ${ }^{1 *}$ \\ From International Society of Sports Nutrition: 9th Annual ISSN Conference and Expo \\ Clearwater, FL, USA. 22-23 June 2012
}

\section{Background}

Many supplements on the market today contain ingredients that claim to increase metabolism and enhance fat loss. Green tea extract and caffeine have well known thermogenic properties. The purpose of this study was to evaluate the effects of proprietary thermogenic dietary supplement Dyma-Burn Xtreme, containing a blend of ingredients including caffeine, green tea extract, raspberry ketones and L-carnitine, on resting energy expenditure and subjective measures of alertness, focus, energy, fatigue, concentration, and hunger.

\section{Methods}

In a double-blind, crossover design 6 male and 6 female subjects $(\mathrm{N}=12,22 \pm 9.5 \mathrm{yrs}, 171 \pm 11.2 \mathrm{~cm}, 76.9 \pm$ $11.2 \mathrm{~kg}, 22.7 \pm 9.5)$, consumed either a 2 capsule serving of Dyma-Burn Xtreme (DBX) or placebo (PLC). Subjects arrived at the lab on a 12 hour fast at 8:00am and had a baseline resting energy expenditure (REE), respiratory exchange ratio (RER), and mood state questionnaire assessed. Subjects then consumed either DBX or PLC and REE and RER were assessed in a supine position for 25 minutes, and questionnaire were assessed at 1-hour (1HR), 2-hours (2HR), 3-hours (3HR), and 4-hours (4HR) post consumption. All data was analyzed utilizing a 2 X5 ANOVA and one-way ANOVA's were used in the case of a significant interaction. A Kruskal Wallis one-way analysis of variance was used for all survey data. A significance value of 0.05 was adopted throughout.

\section{Results}

A significant time effect and group $\mathrm{x}$ time interaction effect were observed among groups for changes in REE $(p>0.05)$. Post-hoc analyses revealed REE levels were significantly different at the $1 \mathrm{HR}$ (DBX: $123.4 \pm 78.2$ vs. PLC: $-3.1 \pm 88.4 \mathrm{kcal} /$ day), $2 \mathrm{HR}$ (DBX: $125.5 \pm 62.2 \mathrm{vs.}$ PLC: $-20.3 \pm 72.6 \mathrm{kcal} /$ day), 3HR (DBX: $142.4 \pm 101.1 .6$ vs. PLC: $9 \pm 114.77 \mathrm{kcal} /$ day), and 4HR (DBX: $147.3 \pm$ 83.5 vs. PLC: $32.1 \pm 86.7 \mathrm{kcal} /$ day) indicating a more profound metabolic response from DBX. There was no significant $(\mathrm{p}<0.05)$ time or interaction effect for RER. Questionnaire data revealed significant increases in alertness and focus $(\mathrm{p}<0.05)$ at the $1 \mathrm{HR}$ time point, energy at the $1 \mathrm{HR} \& 2 \mathrm{HR}$ time points, and decreases in fatigue at the $1 \mathrm{HR}$ time point. There were no significant changes in hunger or concentrations.

\section{Conclusions}

The results of this study revealed that the proprietary blend Dyma-Burn Xtreme ${ }^{\circledR}$ is capable of increasing energy expenditure over a four hour period. In addition, markers of mood state such as focus, alertness, and energy showed significant improvements over a two hour period.

\section{Acknowledgements}

This study was funded by Dymatize Nutrition.

\section{Author details}

'University of Mary Hardin-Baylor, TX, 76513, USA. ${ }^{2}$ Dymatize Nutrition, Dallas, TX, 75234, USA. ${ }^{3}$ University of South Florida, Tampa, FL, 33544, USA.

* Correspondence: cwilborn@umhb.edu

'University of Mary Hardin-Baylor, TX, 76513, USA

Full list of author information is available at the end of the article

(c) 2012 Urbina et al; licensee BioMed Central Ltd. This is an Open Access article distributed under the terms of the Creative Commons Attribution License (http://creativecommons.org/licenses/by/2.0), which permits unrestricted use, distribution, and reproduction in any medium, provided the original work is properly cited. 
doi:10.1186/1550-2783-9-S1-P31

Cite this article as: Urbina et al:: Effects of ingesting Dyma-Burn Xtreme, a thermogenic dietary supplement on metabolic rate and subjective measures of mood state. Journal of the International Society of Sports Nutrition 2012 9(Suppl 1):P31.

Submit your next manuscript to BioMed Central and take full advantage of:

- Convenient online submission

- Thorough peer review

- No space constraints or color figure charges

- Immediate publication on acceptance

- Inclusion in PubMed, CAS, Scopus and Google Scholar

- Research which is freely available for redistribution

Submit your manuscript at www.biomedcentral.com/submit 